\title{
Perceptions of Women on Marriage in Namibia
}

\author{
Nelago Indongo, Lillian Pazvakawambwa \\ University of Namibia, Windhoek, Namibia \\ Email: nkanime@unam.na
}

Received 6 July 2015; accepted 23 August 2015; published 26 August 2015

Copyright (C) 2015 by authors and Scientific Research Publishing Inc.

This work is licensed under the Creative Commons Attribution International License (CC BY). http://creativecommons.org/licenses/by/4.0/

\begin{abstract}
Marital pattern in a Namibian society is predominantly of never married women, and the rates are increasing, while the proportion of those getting married is falling, nevertheless, these proportions decline as age increases. Quantitative research revealed differences in marital status by place of residence, education level and age group suggesting that aspects of culture, marriage practices and customs change over time. Focus group discussions of 6 - 9 participants were conducted to construct supplementary in-depth understanding of women's feelings and attitudes towards marriage in Namibia. Results indicated that women felt that marriage was still important for family formation. The practice of early marriage was reported to be still happening especially in remote rural areas but was on the decline. Marital union choice was dictated by parental guidance, childhood sexual abuse, poverty, culture, age, and religion. Most marriages were not stable and divorces were increasing due to issues of infidelity, poor communication, inpatience and intolerance, step children, financial matters, alcohol and drug abuse, young age at marriage, witchcraft allegations, in-law relationships and even poor cooking. Cohabitation was promoted by exorbitant lobola, marriage costs, modernization, media influences, poverty, and flexibility. The risks associated with cohabiting were gender based violence and passion killings in the event of dissolution and lack of legal representation framework especially with respect to property in the event of partner death. Among the never married women, reasons for not marrying included absence of acceptable mate on the marriage market; need for independence, infertility, fear of abusive relationships, bad past experiences, heart aches, and lack of good married role models to inspire them to also marry.
\end{abstract}

\section{Keywords}

Marriage, Age at First Marriage, Family, Cohabitating, Namibia

\section{Introduction}

Traditional African family patterns are slowly but surely changing due to modernization which is exhibited 
through trends like urbanization. Family patterns that were the norm in traditional rural African societies are gradually being altered and substituted by modern values. In southern Africa the transformation of societies from rural to urban settings has been a significant driving force in revolutionizing family structures (Merrick, 2002). Debate on family patterns in contemporary sub Saharan Africa is usually made in reference to the process of acculturation and urbanization which have helped to shape the modern family structure as well as fostering demographic changes. Demographic changes are being felt in changes in fertility rates, age at marriage (Palamuleni, 2010). The high value traditionally placed on marriage ensured not only its universality but also its occurrence early in life with the consequence that child bearing started early and in most cases continued until late into the productivity span. The institution of polygamy, which sometimes promotes completion for child bearing among co-wives, also contributes to sustained high fertility. Use of modern contraception was traditionally unacceptable as it violated the natural process of procreation. The traditional long period of breastfeeding and postpartum abstinence guaranteed adequate spacing between children. Available evidence suggests that there have been changes in these socio cultural factors over time. Age at marriage appears to have increased; use of modern contraception has increased and improved education especially of women appears to have gradually eroded some of the traditional values placed on child bearing (Bigombe \& Khadiagala, 2003).

Marital status is of interest to a wide range of disciplines. Economists, sociologists, anthropologists and demographers, among others, will often include marital status in their investigations. Marriage constitutes a vital variable that is pivotal for procreation. The distortion of its structure tends to serve as a medium where socio economic changes associated with the main values of culture can be measured. Age at marriage in African communities varies across regions and depends on ethnic practices (Ekane, 2013). In traditional rural African societies the contraction of marriage was dominated by arranged marriages whereby parents usually indulged in the selection of marriage partners for their children especially daughters without their consent. To date, this has been altered to the extent that some countries have adopted policies that strive to advocate for the consent of both parties that are to be married (Tanzania Marriage Act, 1971; Ivory Coast Civil Code, 1964). This does not imply that the involvement of parents in the marriage of their children has stopped. The adoption of these Acts has helped to promote the recognition of the consent of the parties to be married as well as fostered the existence of the acknowledgement that it is the right of prospective partners to select their partners. Despite this development, the selection of marriage partners is still done with the consent of family members.

Namibia has experienced very rapid socioeconomic development since independence in 1991. This has contributed to a significant improvement in the status of women through expanding education and participation in the modernized sectors of the labor force. Such changes have affected attitudes towards marriage and divorce, patterns of marriage, marital dissolution and the role and status of women in the family. This article examines the patterns of marriage in Namibia, examines the trend and suggests reasons for the observed trends.

\section{Method}

A qualitative study was conducted to construct supplementary in-depth understanding of women's feelings and attitudes towards marriage practices and patterns in Namibia. This information was reconciled with quantitative findings from statistical models for the determinants of age at first marriage and factors influencing marital patterns and trends in Namibia using 1992, 2000 and 2006 Namibia Demographic and Health survey data.

In the qualitative design, an interview guide was developed for focus group discussions to gain in-depth understanding on perceptions of Namibian women with regard to matters of marriage, divorce, cohabiting, polygamy, singlehood and widowhood. The group discussions were held in both urban and rural settings in 8 administrative regions of Namibia. Participants comprised of both young and old women who were either married, cohabiting, divorced, widowed and even those who were not yet married. Each focus group discussion was small, consisting of about 6 to 9 participants (giving a total of around 72 participants) to allow full participation of all discussants and was selected using purposive sampling so that in-depth information that supports or substantiates findings would be gathered from individuals believed to be knowledgeable about the subject. Focus group discussions were conducted in Oshana, Otjizondjupa, Zambezi, Kavango West, Omaheke, !Karas, Kunene, and Khomas regions of Namibia. The research instruments were piloted in Khomas region. The proceedings of the discussions were captured by audio tape, which was later transcribed and translated into English where necessary. A trend analysis of age at marriage and marital status was done using NDHS data. 


\section{Results and Discussion}

\subsection{Views Regarding Marriage}

Generally most women agreed that marriage was a good idea so that people could build families. They felt that family formation was especially good under marriage umbrella. Some women reported that people usually form families with people they love and sometimes according to situations they find themselves in. Other women felt that it could be a problem when one does not know how best to form the family. The general feeling across all regions was that family formation was very important, yet difficult step in life, to decide when, and who to marry, or even how many children to have. These were some of their statements:

"I believe that before a family is formed, marriage should come first"-Oshana region, Young Woman, Rural.

"Marriage is good because it keeps the family intact" Omaheke Region, Urban, Older woman.

"It is normal, ok and great. Everybody needs and deserves someone to spend their entire life with."-Omaheke Region, Urban, Young woman.

"It is a good thing, you are fully responsible for your husband, children and family and all your children are from the same father."-Omaheke Region, Rural, Older woman.

These statements seem to suggest that the women felt the need for family intactness, companionship, and a binding fabric of moral values.

There were varying responses when it came to the ideal age for a woman to get married. The suggested ages ranged from 25 to 35 years of age. They felt that after 25 years of age, the woman is likely to be done with schooling, she is mature, she is above the legal age of marriage, her mind is clear, she can make rational decisions, and others felt that a woman needs to enjoy herself before she gets married. The postponement of marriage is also reflected by the increase in age at first marriage. Analysis from the NDHS also showed a decrease in the proportion of married women from $29.0 \%$ in 1992, 23.4\% in 2000 and $20.4 \%$ in 2006. The results also show that the mean age at first birth has remained relatively constant over the years, while the mean age at first marriage has considerably increased from 21 years in 1992 to almost 23 years in 2006. This is also consistent with earlier studies (Pauli, 2010) who reported that the median age at marriage among ever married Fransfonteiners is 30 years and the average age is 32 years.

In southern Africa, governments have put in place legislations to protect girls from early marriage. According to Africa Policy Forum, 2013, the minimum legal ages at marriage in years have been stipulated as follows: Lesotho, 21; Malawi, 15; Namibia, 18; South Africa, 18; Mozambique, 18; Zambia, 19 and Zimbabwe, 15. In South Africa, although the legal age for individuals to marry is 18, most girls marry between 25 and 30 years of age and men between 27 and 33 years of age. This means that marriage does not take place at very early ages as it is the case with traditional societies (Palamuleni, 2010). Rakgoasi and Gaise (1999) also found that the singulate mean age at marriage for Botswana in 1991 was 28 years for female and 30.8 year for males. Differentials in marriage form between urban and rural areas are that traditional marriages are a rare phenomenon in urban areas. Traditional marriages in southern Africa are generally more common among non-urban dwellers than civil marriages (Budlender et al., 2004) (Figure 1 and Figure 2).

\subsection{Forms of Marital Status in Namibia}

All forms of marital unions were reported namely, the married (through church, magistrate's court, customary), cohabiting, never married, divorced, and widowed. The most common forms of marital union in the !Karas region was cohabiting while some women were married at church, at the magistrates court, traditional marriages but there were no polygamous unions reported. In the Kunene region polygamy was the most common marital union. In Khomas, Otjozondjupa, and Kavango there were various forms even though the majority were mostly cohabiting unions.

"Our community has very few polygamous unions, only by rich business men or very traditional men. Women turn to polygamous unions for security"-Oshana Region, Older woman, rural.

"Men can marry more than one wife and there are no restrictions, they can marry as many women as they want to.” Kunene Region—rural, Older woman.

"Especially if there is a rich man in the community, a lot of women want to be married to him for good living and men still have that pride of saying he can marry any woman he likes". Zambezi Region, rural, Older woman

"Yes, many men marry more than one wife because the first wife is unable to give birth (infertility), that particular husband is forced to find another wife". 


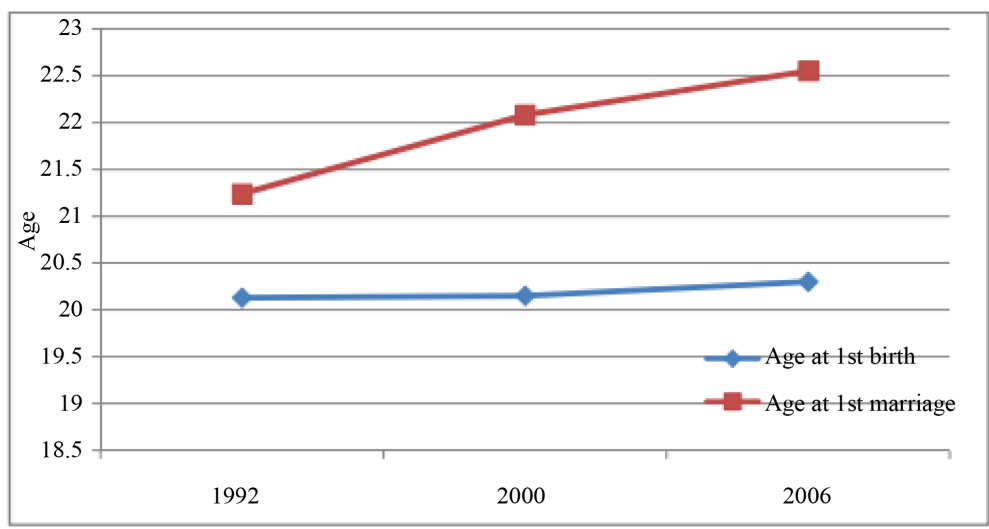

Figure 1. Average age at first marriage and first birth of women of childbearing age by year, Namibia.

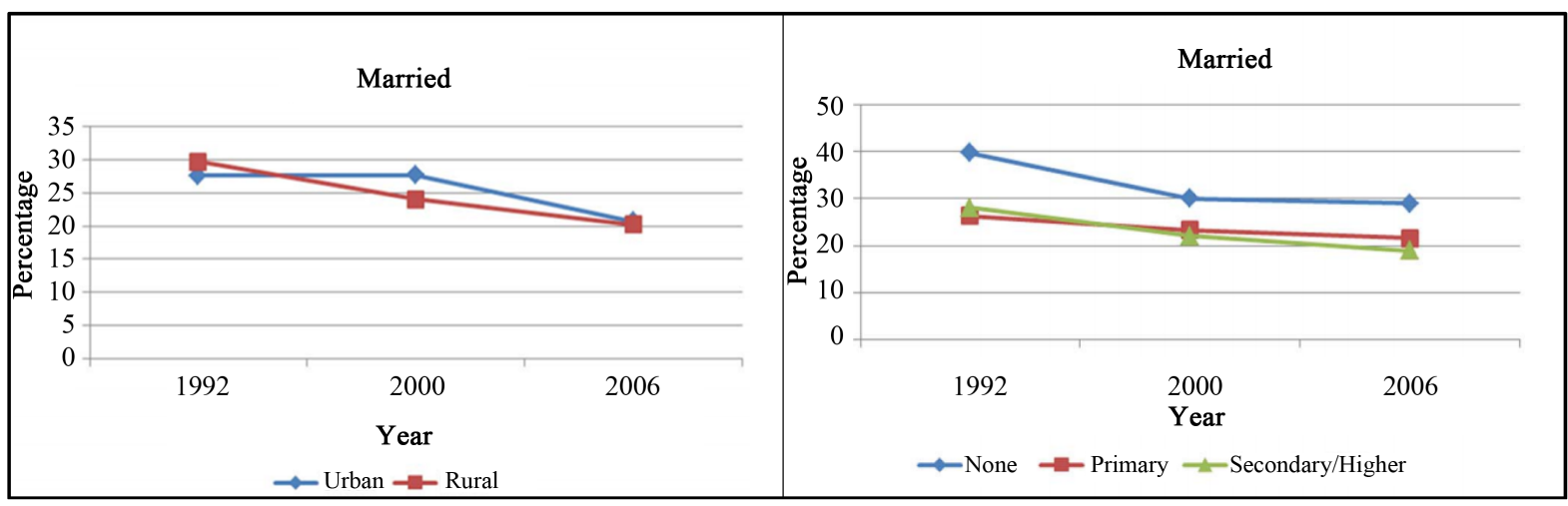

Figure 2. Percentage of married women by place of residence and by highest educational level.

\subsubsection{Never Married Women}

In all regions investigated, there were women who had never married. Reasons for deciding never to marry included risks of spouse infidelity, absence of perfect match on the marriage market, no interest in marriage and independence, infertility fears, fear of abusive relationships, risks of being broken hearted, and lack of role models already in marriage to emulate. It was noted that even though a considerable number of women decided not to marry, most of them do not abstain from sexual activities which make them vulnerable to STI and HIV/AIDS. Analysis from the NDHS also showed that over half of the women interviewed in all the years were never married (50.0\% in 1992, 50.3\% in 2000 and 56.6\% in 2006). This showed an increase of $6.6 \%$ for the period 1992-2006. Among the never married, the proportion in the urban areas was relatively lower than in the rural areas between 1992 and 2000, but this changed in 2006. The analysis therefore revealed that marital patterns in a Namibian society is predominantly of never married women, and the rates are increasing, while the proportion of those getting married is falling, nevertheless, these proportions decline as age increases (Figure 3).

Because maybe "they cannot bear children, cannot be a wife material, and men of this generation don't marry uneducated women, so women who are uneducated tend to lose hope of getting married"-Zambezi Region, Rural, Young Woman

"They do not want marriage that will not last long, if they are able to look after themselves i.e. have enough money"-Karas region, Rural, Old woman.

"They have seen married men wanting to take other women and at the same time ill-treating their wives. The unmarried women are watching!”-!Karas region, Rural Young Woman.

"Yes, there are women who never married, some were never proposed, while others choose a life of celibacy and others may not have found a suitable partner", Oshana Region, Young woman, Urban.

\subsubsection{Polygamous Unions}

Women in the !Karas and Khomas region reported that their regions did not have polygamous unions. However, 


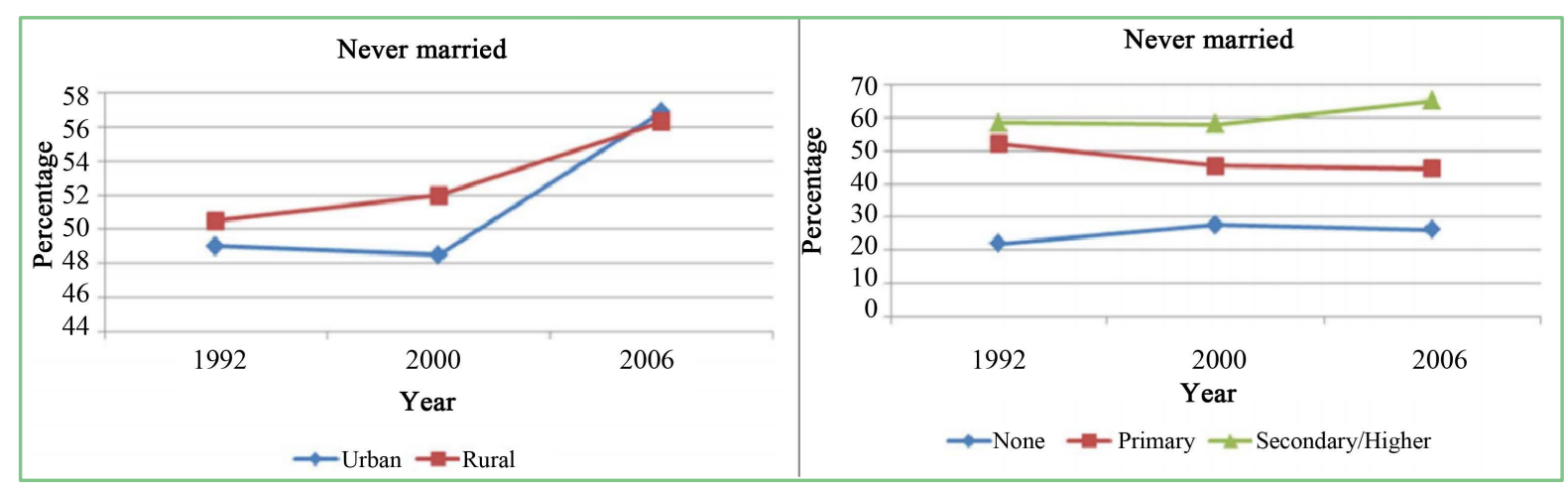

Figure 3. Percentage of never married women by place of residence and by highest educational level.

traces of polygamy were reported in the Oshana, Kavango West, Otjozondjupa and Zambezi regions. Interestingly, polygamy was also perceived as a symbol of status and as a tool to reduce HIV infection as one woman put it,

"But polygamous unions in a sense build a network of support for children and women and somehow reduce the risk of sexually transmitted diseases as cheating is limited especially if the wives of the one husband are a faithful team”, Oshana Region, young woman, rural.

On the other hand, other risks of polygamous unions cited by some women included the spread of sexually transmitted diseases (STI) and HIV/AIDS, jealous among the wives of one husband, which in some cases could lead to fighting, food poisoning, and witchcraft. The women reported that the benefits of polygamy were mainly for the man as there were no benefits at all cited for the women except for financial security in some cases. A big problem of polygamy raised by one of the women was stated as follows, "since each wife will have a set of children born to her, once those children grow up, they will also become jealous of each other and they usually fight over the inheritance of their father's property", Zambezi Region, rural, Older woman.

\subsubsection{Cohabiting Unions}

Cohabiting unions were reported in all the regions investigated. The risks of cohabiting cited where that when there is no more love in the relationship and the other partner wants to leave the relationship, that's when domestic, gender-based violence and passion killings happen. Cohabiting seemed to be the most common and increasing marital form in Namibia. Similar results were obtained by Bocquier and Khasakhal (2009) in Kenya were cohabitation without formal marriage was the most prominent form of union especially among the younger generation and appeared also to be on the increase. Unlike for women, for men, the timing of family formation was more dependent on human capital acquisition than on cultural factors. Studies in Southern Africa revealed delays in the onset of marriage, a clear-cut trend of proportions of never married, decreasing prevalence of evermarried, increasing cohabitation and variation in marriage patterns across population groups (Mokomane, 2006; Shapiro \& Grebreselassie, 2014; Palamuleni \& Palamuleni, 2011). The proportion of cohabitating couples in Namibia has remained almost constant, below 20\%, for the period 1992 to 2006, but persistently within the same range as those currently married. Comparison with other countries in the region show similarities with South Africa, while for Malawi, Mozambique and Zambia, marriage patterns are dominated by the married group (Larson \& Holmann, 1994; Arnaldo, 2004). Factors promoting cohabiting unions in Namibia included exorbitant lobola, marriage and general marriage costs, modernization, media influences, poverty, "trial marriage”, and flexibility (Figure 4).

"Cohabitation exists because they are unable to afford expenses for example, if they are renting together they reduce their costs by dividing the expenses between themselves"-Zambezi Region Young woman.

"with changes in times and modernization among people especially the youth engages in cohabiting relationships. One of the factors influencing this is modern time culture, media and the internet"-Oshana region, Young woman, urban.

The idea of the traditional family is continuously being challenged; more adults are choosing to remain single and cohabit instead of being legally married (Ludidi, 2015). Compared to marriage, cohabitation gives both partners an opportunity to be in a stable relationship without the pressures and commitment of marriage. These 


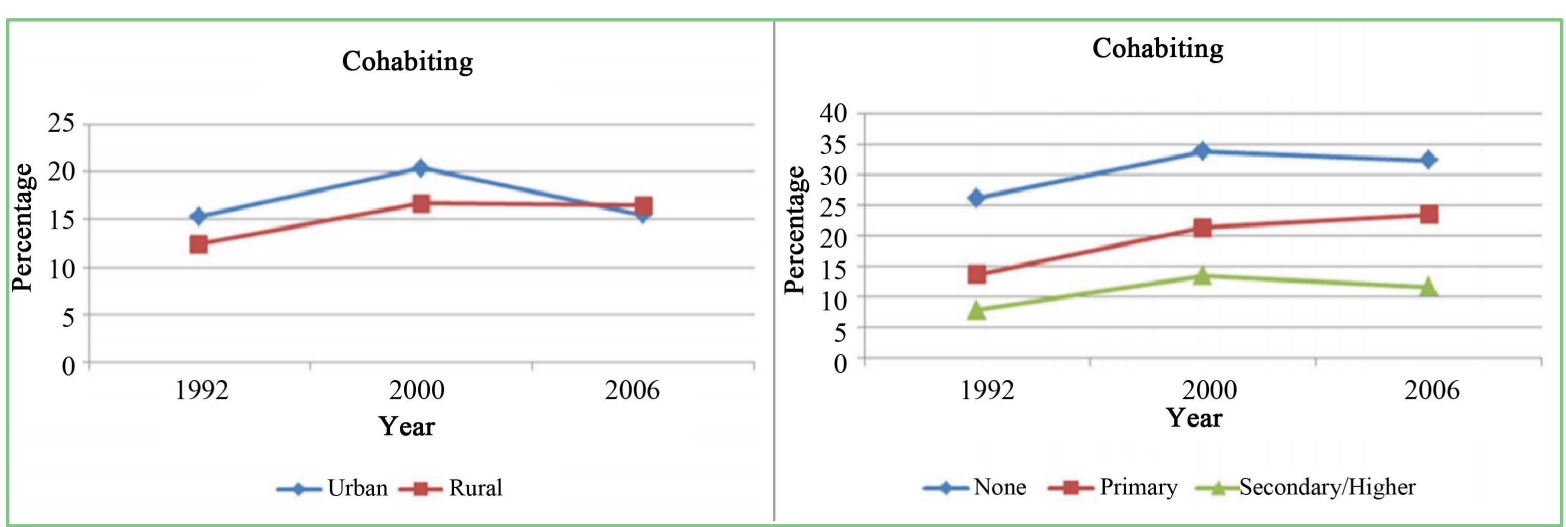

Figure 4. Percentage of cohabiting women by place of residence and by highest educational level.

changes in living arrangements have resulted in changes in the delay of childbearing. The evolution of traditions and culture has brought about some level of comfort with modern day living arrangements. Traditionally, husband and wife would move in together once they have been bound by marriage. Living arrangements in the new informal households are no longer based on this premise. Residence in these types of households is now associated with both economic changes and with the value shifts that accompany modernisation: it is associated with high levels of labour market participation by women and with values that stress individual self-determination (Raley, 2001: p. 66). Cohabitation appears to provide young women with the opportunity of being in a stable relationship while pursuing their education and establishing themselves in a career before committing themselves to motherhood. Cohabitation is also is associated with a more equal allocation of domestic roles than is the case in married couples (de Singly \& Ciccheli, 2003: p. 338).

\subsubsection{Divorced Women}

Divorces were reported to be taking place in all regions and the reasons for divorcing included domestic violence, alcohol and drug abuse, inadequate income, poor sex performance, having feelings for someone else and cheating, witchcraft, and in some cases if the wife was not able to cook properly. The general feeling among women was that most of the marriages were not stable and that divorces were on the increase. Factors causing marital instability and divorces cited ranged from infidelity, ineffective communication, impatience and intolerance, step children, financial matters, alcohol and drug abuse, young age at marriage, poor sexual relations, witchcraft allegations, negative in-law relationships and even poor cooking. For more stable marriages, the women proposed continuous pre and post marriage counselling by older and more experienced and exemplary pastors, religious and moral education, programs to promote faithfulness in married couples.

"Cheating your partner, Marriage can last if the husband is not cheating"-Zambezi region young woman, rural.

"Husbands have other girlfriends who are usually younger and more beautiful than the wife in the house and this leads to divorce"-Khomas region, old woman, urban.

"Marriages are stable for elderly couples compared to the younger couples because the young ladies are educated and they do not want to be undermined and tossed since most men depend on women for everything that has to do with house chores"-Zambezi Region, rural, young woman.

"Drinking alcohol as there is always quarreling and fighting after drinking".

\subsubsection{Widowhood}

In all regions there were a considerable number of widows. Causes of death leading to widowhood for most women were mostly due to sickness and accidents. Widows in most of the regions were facing various challenges. Challenges faced by the widows ranged from property inheritance, widow inheritance, poverty, suspicion and accusations, remarriage challenges and stigmatization. Recent trends indicate that widowhood is becoming less common, largely because more people either never marry or are separated or divorced (Palamuleni, 2010). Most studies on widowhood have focused on women, partly because widows outnumber widowers by nearly five to one. It is estimated that half of all marriages end with the death of the husband, whereas only 
one-fifth end with the death of the wife in Western societies and women generally outlive men and men usually marry women who are younger than they are. In Africa, different societies attach very different customs and values to widowhood, and these have a strong influence on how it is experienced. Most widows go through an intense grieving process early in widowhood, marked by feelings of depression, mood changes, disrupted sleep pattern, obsessive thoughts about the deceased and disorientation (Luke, 2001). However, this decrease significantly within a year and many widows and widowers begin to develop new strengths and remake their social network to include new friends and contacts.

\section{Conclusion}

A crucial factor that has led to increased childbearing amongst single women is the fact that increasingly, the stigma attached to bearing children out of wedlock is disappearing. It is no longer considered taboo for a woman to choose to have children outside the confines of marriage, in fact in some societies it is becoming a very normal occurrence. In more liberal and secular societies the stigma has been disappearing. With women no longer having to deal with the added social pressure of being frowned upon when they choose to bear children out of wedlock, the number of women making this choice has been on the increase. The fact that the stigma is dissipating has meant that those who have a longing to be mothers and those who have no financial constraints are free to bear children (Seltzer, 2000: p. 1249).

The ability of single women to choose to bear children, financial emancipation and the disappearing stigma of single-parenthood has enabled women to have children outside the confines of marriage if they so choose.

Women's education affects childbearing decisions and the exercise of reproductive rights in several ways. An increase in women's educational level is likely to enhance their ability and power in reproductive decisionmaking (Sippel, 2008: p. 15). The appearance of individual values and the search for personal autonomy are followed by an increase in education. Educated women tend to delay marriage and childbearing which often results in the probability of both not happening (Correa, 1994: p. 24). When women and girls begin to attend school and receive the same education as boys, the doors to their autonomy and other value systems are opened to them. Education improves women's ability to selectively utilise a wide range of ideas and values for personal enhancement. Exposure to new ideas and ways of thinking mean that educated women are most likely to exercise greater autonomy in childbearing decisions (Duvander et al., 2010: p. 47). Reproductive rights are not only about allowing women to have the freedom to choose how many children they want, they are also about allowing women the freedom to decide not to have children. When women become educated, they are less likely to choose to marry and have children. Studies have found that generally, educated women who delay marriage often end up not marrying because by the time they have made progress in their careers; they no longer see a need to marry. Increased education means delayed marriage, which in turn means in many instances that childbearing is also delayed (Gerntholtz, Gibbs, \& Willan, 2011: p. 1).

Marital union choice was dictated by parental guidance, childhood sexual abuse, poverty, culture, age, and religion. Factors causing marital instability and divorces cited ranged from infidelity, ineffective communication, impatience and intolerance, step children, financial matters, alcohol and drug abuse, young age at marriage, poor sexual relations, witchcraft allegations, negative in-law relationships and even poor cooking. For more stable marriages, the women proposed continuous pre and post marriage counselling by older and more experienced and exemplary pastors, religious and moral education, programs to promote faithfulness in married couples. The study demonstrated the fact that demographic and socio-economic characteristics have important and similar effects for all marriage patterns. These factors can play a very important role in policy formulation. As observed in other countries in southern Africa, there is a social change in the Namibian society as reflected in the emerging marital patterns of declining marriages, rising cohabitation and rising singlehood. However in Southern Africa marriage still remains a predominant nuptiality pattern, and common among the less educated and employed, but lower odds in urban areas. It can be concluded that marital patterns have undergone significant transformation over the past two decades in Namibia and policymakers should be on the objective look out for the impact of this dynamism.

\section{References}

Arnaldo, C. (2004) Ethnicity and Marriage Patterns in Mozambique. African Population Studies, 19, 143-164.

Bigombe, B., \& Khadiagala, G. M. (2003). Major Trends Affecting Families in Sub-Saharan Africa. 
http://www.un.org/esa/socdev/family/Publications/mtbigombe.pdf

Bocquier P., \& Khasakhala, A. (2009). Factors Influencing Union Formation in Nairobi, Kenya. Journal of Biosocial Sciences, 41, 433-455. http://dx.doi.org/10.1017/S0021932009003319

Budlender, D., Ntebaleng, C., \& Sandile, S. (2004). Marriage Patterns in South Africa: Methodological and Substantive Issues. Southern African Journal of Demography, 9, 1-25.

Correa, S. (1994). Population and Reproductive Rights: Feminist Perspectives from the South. London: Zed Books Ltd.

De Singly, F., \& Cichelli, V. (2003). Contemporary Families: Social Reproduction and Personal Fulfilment. In D. Kertzer, \& M. Barbagli (Eds.), History of the European Family, Volume 3: Family Life in the Twentieth Century (pp. 311-349). New Haven: Yale University Press.

Duvander, A. Z., Lappegard, T., \& Andersson, G. (2010). Family Policy and Fertility: Fathers’ and Mothers’ Use of Parental Leave and Continued Childbearing in Norway and Sweden. Journal of European Social Policy, 20, 45-57. http://dx.doi.org/10.1177/0958928709352541

Ekane, D. (2013). http://su.diva-portal.org/smash/get/diva2:602444/FULLTEXT01.pdf

Gerntholtz, L., Gibbs, A., \& Willan, S. (2011). The African Women’s Protocol: Bringing Attention to Reproductive Rights and the MDGs. Public Library of Science Medicine, 8, 1-4. http://dx.doi.org/10.1371/journal.pmed.1000429

Larson, J. H., \& Holman, T. B. (1994). Premarital Predictors of Marital Quality and Stability. Family Relation, 43, $228-237$. http://dx.doi.org/10.2307/585327

Ludidi, W. Z. (2015). Sociological Factors Influencing Childbearing Decisions in Rural Areas, with Specific Reference to the Eastern Cape. Unpublished Ph.D. Thesis, Johannesburg: University of Johannesburg.

Luke, N. (2001). The Cultural Significance of Widowhood: Widow Inheritance and the Position of Luo Widows in the 1989 Kenya Census. Paper Prepared for the Virtual Conference on African Households, Population Studies Centre, University of Pennsylvania, Philadelphia, 21-24 November 2001.

Merrick, T. (2002). Population and Poverty: New Views on an Old Controversy.

Mokomane, Z. (2006). Cohabiting Unions in Sub-Saharan, Explaining Botswana's Exceptionality. Journal of Comparative Family Studies, 37, 25-42.

Palamuleni, L. G., \& Palamuleni, M. E. (2011). Spatial Variation of Age at Marriage in South Africa. Journal of Social Science, 29, 39-46.

Palamuleni, M. E. (2010). Recent Marriage Patterns in South Africa 1996-2007. Bangladesh e-Journal of Sociology, 7, 4770.

Pauli, J. (2010). Demographic and Anthropological Perspectives on Marriage and Reproduction in Namibia. In W. Möhlig, O. Bubenzer, \& G. Menz (Eds.), Towards Interdisciplinarity (pp. 203-232). Cologne: Heinrich-Barth-Institut.

Rakgoasi, \& Gaise (1999). Population Growth and Composition. In S. K. Gaise, \& R. G. Majelantles (Eds.), Demography of Botswana: Change in Population Size and Structure (pp. 33-76). Gaborone: Mmegi Publishing House.

Raley, R. K. (2001). Increasing Fertility in Cohabiting Unions: Evidence for the Second Demographic Transition in the United States? Demography, 38, 59-66. http://dx.doi.org/10.1353/dem.2001.0008

Seltzer, J. A. (2000). Families Formed Outside Marriage. Journal of Marriage and Family, 62, 1247-1268. http://dx.doi.org/10.1111/j.1741-3737.2000.01247.x

Shapiro, D., \& Gebreselassie, T. (2014). Marriage in Sub-Saharan Africa: Trends Determinants and Consequences, Population Research Review, 33, 229-225. http://dx.doi.org/10.1007/s11113-013-9287-4

Sippel, S. (2008). Achieving Global Sexual and Reproductive Health and Rights. Human Rights, 35, 13. 